\title{
Betacellulin inhibits osteogenic differentiation and stimulates proliferation through HIF-1 $\alpha$
}

\author{
Damian C. Genetos • Rameshwar R. Rao • \\ Martin A. Vidal
}

Received: 19 August 2009 / Accepted: 14 January 2010/Published online: 18 February 2010

(C) The Author(s) 2010. This article is published with open access at Springerlink.com

\begin{abstract}
Cellular signaling via epidermal growth factor (EGF) and EGF-like ligands can determine cell fate and behavior. Osteoblasts, which are responsible for forming and mineralizing osteoid, express EGF receptors and alter rates of proliferation and differentiation in response to EGF receptor activation. Transgenic mice over-expressing the EGF-like ligand betacellulin (BTC) exhibit increased cortical bone deposition; however, because the transgene is ubiquitously expressed in these mice, the identity of cells affected by BTC and responsible for increased cortical bone thickness remains unknown. We have therefore examined the influence of BTC upon mesenchymal stem cell (MSC) and pre-osteoblast differentiation and proliferation. BTC decreases the expression of osteogenic markers in both MSCs and pre-osteoblasts; interestingly, increases in proliferation require hypoxia-inducible factor-alpha (HIF$\alpha$ ), as an HIF antagonist prevents BTC-driven proliferation. Both MSCs and pre-osteoblasts express EGF receptors $E r b B 1, E r b B 2$, and ErbB3, with no change in expression under osteogenic differentiation. These are the first data that demonstrate an influence of BTC upon MSCs and the first to implicate HIF- $\alpha$ in BTC-mediated proliferation.
\end{abstract}

The authors are grateful to the Center for Equine Health (UC Davis) for funding to support this study.

D. C. Genetos $(\bowtie) \cdot$ R. R. Rao $\cdot$ M. A. Vidal

Department of Surgical and Radiological Sciences,

School of Veterinary Medicine, University of California at Davis,

2112 Tupper Hall,

Davis CA 95616, USA

e-mail: dgenetos@ucdavis.edu

R. R. Rao

e-mail: ram.rao@gmail.com

M. A. Vidal

e-mail: mavidal@ucdavis.edu
Keywords Stem cell · Osteoblast · Differentiation · Proliferation · Betacellulin · Cell culture $\cdot$ Human

\section{Introduction}

The skeleton continually undergoes alterations in size and shape in response to humoral, mechanical, and paracrine stimuli. Degradation of pre-existing bone by osteoclasts and ensuing replacement with osteoid by osteoblasts require concerted activity in order to maintain skeletal homeostasis and to prevent pathologic conditions such as osteoporosis or osteopetrosis. Osteoblast number is partially governed by the proliferation and osteogenic differentiation of mesenchymal stem cell (MSC) precursors; hence, stimuli that enhance MSC number or osteogenic differentiation emerge as ideal methods to combat bone loss resulting from pharmacology or aging.

Epidermal growth factor (EGF) mediates diverse processes of proliferation, differentiation, adhesion, and survival (Citri and Yarden 2006; Yarden and Sliwkowski 2001). The EGF family of ligands consists of EGF, amphiregulin, betacellulin (BTC), epiregulin, epigen, heparin-binding EGF-like growth factor (HB-EGF), and transforming growth factor-alpha (TGF- $\alpha$; Harris et al. 2003; Xian 2007). EGF signaling occurs through ErbB receptor tyrosine kinases, of which ErbB1/EGF-R is bound by all seven family members. Three members (EGF, amphiregulin, and TGF- $\alpha$ ) can only bind to ErbB1, whereas BTC, epiregulin, and HB-EGF can also bind to ErbB4 to form ErbB1/ErbB4 heterodimers. ErbB2, although lacking any known cognate ligand, is the preferred co-receptor for ErbB1, and the heterodimerization of ErbB2 and ErbB1 generates more potent signaling than ErbB1 homodimers (Qin et al. 2005; Yarden 2001; Yarden and 
Sliwkowski 2001); ErbB3 is a pseudokinase and therefore lacks any traditional catalytic kinase domain. Once bound by EGF or EGF-like ligand, homo- or heterodimerized ErbB receptors initiate multiple signaling pathways that affect proliferation, survival, and differentiation and that are mediated Ras-Raf-mitogen-activated protein kinase (Ras-Raf-MAPK; Yarden and Sliwkowski 2001), the phosphatidyl-inositol-3-kinase/Akt pathway (Xian 2007), and phospholipase C- $\gamma /$ protein kinase C (Yarden and Sliwkowski 2001).

EGF and related ligands exert disparate effects upon osteoblast differentiation and proliferation. In vitro studies have revealed that EGF inhibits bone nodule formation (Antosz et al. 1987) and decreases alkaline phosphatase (ALP) activity (Nicolas et al. 1990). Similar findings have been reported for osteoblastic cells treated with amphiregulin (Qin et al. 2005). Further, over-expression of ErbB1 in ROS rat osteosarcoma cells decreases the expression of osteoblastic markers (Chien et al. 2000). Comparable results are observed with in vivo models. EGF transgenic mice, under the control of a $\beta$-actin promoter, demonstrate a $20 \%-50 \%$ reduction in body weight (Wong et al. 2000) and decreased cortical bone thickness compared with wildtype controls (Chan and Wong 2000). Similar observations, including impaired longitudinal growth and overall disproportionate skeletal growth, are detected in mice transgenic for BTC (Schneider et al. 2005). Whereas EGF suppresses the osteoblastic phenotype, it demonstrates mitogenic effects upon osteoblastic cells (Loza et al. 1995; Nicolas et al. 1990; VandePol et al. 1989), as do amphiregulin and TGF- $\alpha$ (Qin et al. 2005). Thus, a general theme regarding EGF signaling in bone seems to be increased proliferation and decreased osteogenic differentiation. Schneider et al. (2009) have recently demonstrated that BTC transgenic mice have enhanced cortical, but reduced trabecular, bone thickness. To date, however, no study has examined the influence of BTC upon osteoprogenitor proliferation or differentiation. We report that BTC attenuates the osteogenic differentiation of MSC and committed preosteoblastic cells, whilst simultaneously increasing their proliferation through a mechanism involving the stabilization of hypoxia-inducible factor (HIF). These are the first data to demonstrate an influence of BTC upon MSC and the first to implicate HIF in BTC-mediated proliferation.

\section{Materials and methods}

Cell culture Human MSCs (hMSCs) were purchased from Lonza; cells were isolated from iliac crest bone biopsies from a 19-year-old male African-American, a 20 -year-old male African-American, and an 18-year-old male Caucasian with no known pathologic conditions. hMSCs (pas- sages 2-6) were cultured in $\alpha$-MEM supplemented with $10 \%$ fetal bovine serum (FBS; Invitrogen) and $1 \%$ penicillin/streptomycin $(\mathrm{P} / \mathrm{S}$; Invitrogen) and maintained in a humidified incubator at $37^{\circ} \mathrm{C}$ with $5 \% \mathrm{CO}_{2}$. MC3T3-E1, clone 14, pre-osteoblastic cells were purchased from American Type Culture Collection and cultured in $\alpha$ MEM supplemented with $10 \%$ FBS and $1 \% \mathrm{P} / \mathrm{S}$ and maintained in a humidified incubator at $37^{\circ} \mathrm{C}$ with $5 \%$ $\mathrm{CO}_{2}$. Cells were sub-cultured with $0.05 \%$ trypsin/EDTA when $80 \%$ confluent.

Osteogenic differentiation hMSCs or MC3T3-E1 cells were seeded into 6-well plates at a density of 3000 cells $/ \mathrm{cm}^{2}$. When $70 \%$ confluent, media was replaced with osteogenic differentiation media consisting of $10 \% \mathrm{FBS}, 1 \% \mathrm{P} / \mathrm{S}$, $5 \mathrm{mM} \beta$-glycerophosphate acid (VWR International) and $50 \mu \mathrm{g} / \mathrm{ml} \mathrm{L}$-ascorbic acid 2-phosphate (Waco) in $\alpha$-MEM (Invitrogen).

RNA extraction and quantitative polymerase chain reaction Total RNA was collected with RNeasy Mini kit (Qiagen) according to the manufacturer's instructions and including on-column digestion of genomic DNA. RNA quality was assessed by the ratio of absorbance at $260 \mathrm{~nm}$ and $280 \mathrm{~nm}$. Total RNA $(0.2-1 \mu \mathrm{g})$ was reverse-transcribed with a Superscript First-Strand Synthesis System (Invitrogen). Quantitative reverse transcription with the polymerase chain reaction (RT-PCR) was performed by using the TaqMan Universal PCR Master Mix (Applied Biosystems) on a Mastercycler realplex2 (Eppendorf); proprietary primers and probes, whose sequences are not disclosed, were purchased from Applied Biosystems. Amplification conditions were $50^{\circ} \mathrm{C}$ for $2 \mathrm{~min}, 95^{\circ} \mathrm{C}$ for $10 \mathrm{~min}$, followed by 40 cycles at $95^{\circ} \mathrm{C}$ for $15 \mathrm{~s}$ and $60^{\circ} \mathrm{C}$ for $30 \mathrm{~s}$. Quantitative PCR results were first normalized to ribosomal protein 13 (Rpll3) transcript level to yield $\Delta \mathrm{C}_{\mathrm{t}}$. Results are expressed as $2^{-\Delta \mathrm{Ct}}$ or $2^{-\Delta \Delta \mathrm{Ct}}$, after Livak and Schmittgen (2001).

ALP activity assay Whole cell protein lysates were collected on days 3,7 , or 21 in $0.1 \%$ Triton X-100, $10 \mathrm{mM}$ TRIS $\mathrm{pH} 8,1 \mathrm{mM}$ EDTA, and protease inhibitor cocktail (Calbiochem). Lysates $(10 \mu \mathrm{l})$ were incubated with $p$ nitrophenol phosphate (Sigma) and incubated at $37^{\circ} \mathrm{C}$ for $30 \mathrm{~min}$. The reaction was terminated with the addition of $0.02 \mathrm{~N} \mathrm{NaOH}$, and activity was recorded by measuring absorbance $(450 \mathrm{~nm})$ on a microplate reader.

Proliferation assays Cells were seeded into $60-\mathrm{mm}$ dishes at a density of $9500 / \mathrm{cm}^{2}$ and cultured for 2 days, after which the medium was removed and replaced with BTC $(0.5-500 \mathrm{ng} / \mathrm{ml})$ in reduced-serum $(2 \%$ FBS $)$ medium. As a positive control for proliferation, a subset of cells was cultured in high-serum (20\% FBS) medium in the absence 
of BTC. Cells were collected 4 days later by trypsinization and counted by using a Countess automated cell counter (Invitrogen). To determine the influence of HIF- $\alpha$ isoforms upon BTC-mediated proliferation, cells were treated with 10-25 $\mu \mathrm{M}$ YC-1, a small molecule post-transcriptional antagonist of HIF- $1 \alpha$ accumulation (Chun et al. 2004). Proliferation under these conditions was assessed as above.

Western immunoblotting Cells were briefly washed with phosphate-buffered saline, and whole-cell protein lysates were collected in $0.1 \%$ Triton X-100, $10 \mathrm{mM}$ TRIS pH 8 , $1 \mathrm{mM}$ EDTA, supplemented with a protease and phosphatase inhibitor cocktail (Calbiochem). Samples were electrophoresed onto $7.5 \%$ TRIS-HCl gels (Bio-Rad), resolved onto $0.2-\mu \mathrm{m}$ nitrocellulose membranes, and blocked in nonfat milk in TRIS-buffered saline supplemented with $0.1 \%$ Tween-20. Immunoreactivity against HIF-1 $\alpha$ (1:200; Cayman Chemical) or $\beta$-actin $(1: 1000$; Abcam) was visualized with appropriate horseradish-peroxidase-conjugated antibodies (Jackson Immunoresearch) and ECL Plus Western Blotting Detection Reagents (GE Healthcare). Densitometric analysis was performed with Adobe Photoshop.

Statistical analysis The experimental design involved repeated measures analysis or dose-response comparisons with negative or positive controls. The data were assessed for normality with the Shapiro Wilk test, and analysis of variance was performed by using Proc GLM (SAS 9.1.2, SAS Institute). Either Tukey's or Dunnet's tests were used for post-hoc comparisons. Student's $t$-test was used for pairwise comparisons of the least square means to examine interaction effects. Statistical analyses and the type I error was maintained at $<0.05$ for all comparisons. Data are reported as arithmetic means $\pm \mathrm{SE}$ or fold-change to BTCfree controls $\pm \mathrm{SE}$.

\section{Results}

BTC inhibits osteogenic differentiation of mesenchymal and pre-osteoblastic cells

We first examined the influence of BTC upon MSC differentiation toward the osteogenic lineage. hMSCs were cultured under osteogenic conditions and $0.5-500 \mathrm{ng} / \mathrm{ml}$ BTC for $3,7,14$, or 21 days. ALP activity increased with time in culture in BTC-free controls, indicating progression of hMSCs toward an osteoblastic phenotype (Fig. 1a). We observed a trend for attenuation of ALP activity compared with BTC-free controls at all time points and in all concentrations of BTC. The difference in ALP activity between BTC-free controls and cells under treatment were

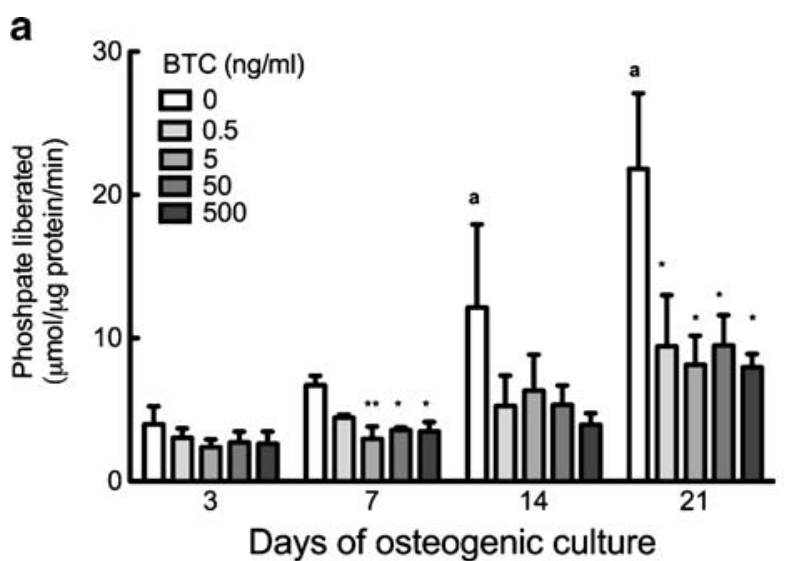

b
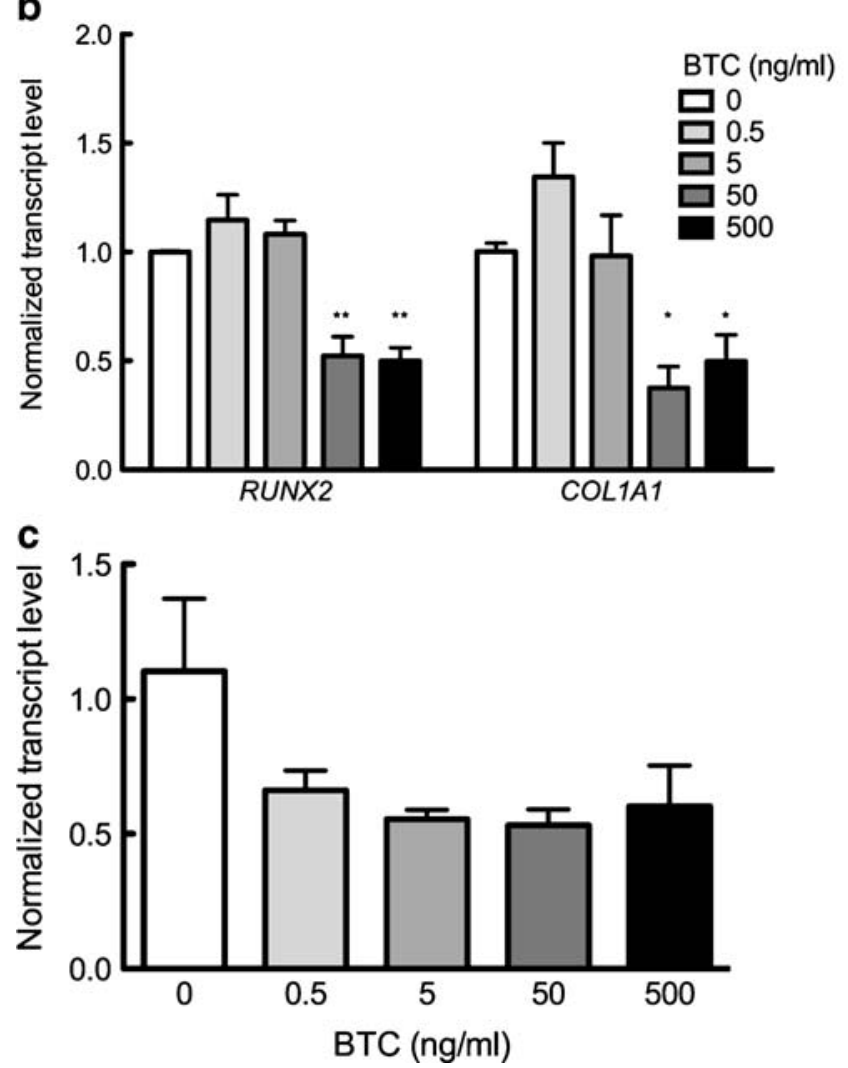

Fig. 1 Effect of BTC on osteogenesis. hMSC or MC3T3-E1, under osteogenic conditions, were cultured in the presence of $0-500 \mathrm{ng} / \mathrm{ml}$ BTC. a Alkaline phosphatase activity assays of hMSCs after 3, 7, 14, or 21 days. b Quantitative polymerase chain reaction (qtPCR) analysis of RUNX2 and COL1A1 expression in hMSCs after 7 days of BTC treatment. $\mathbf{c}$ qtPCR analysis of Colla 2 expression in MC3T3-E1 cells after 7 days of BTC treatment. Bars Means \pm SE. ${ }^{*} P<0.05$ compared with BTC-free culture within same timepoint; $* * P<0.01$ compared with BTC-free culture within same timepoint; ${ }^{a} P<0.05$ compared with BTC-free culture on day $3 ; n=3-5$ per experiment per time point

significant on day $7(5,50$, or $500 \mathrm{ng} / \mathrm{ml})$ and day 21 (5 and $500 \mathrm{ng} / \mathrm{ml}$; Fig. 1a). BTC-treated cells revealed significant increases in ALP activity at day 21 compared with cells treated with the same dose of BTC and collected at day 3, indicating that BTC slowed, but did not arrest, the osteogenic 
differentiation of MSCs. In further support of an inhibitory influence of BTC upon osteogenic differentiation, BTC at 50 or $500 \mathrm{ng} / \mathrm{ml}$ significantly attenuated transcription of the osteogenic transcription factor RUNX2 and osteoblast marker COL1A1 relative to BTC-free cultures (Fig. 1b). Similar trends were observed for both genes in cultures collected after 14 and 21 days of BTC treatment, but this was without statistical significance; after day 28 , no significant effect of BTC was deteted on RUNX2 or COL1A1 expression (data not shown). Interestingly, the expression of osteocalcin, a marker of mature osteoblasts, was not significantly affected by BTC treatment (not shown). We examined the possibility that a stimulatory influence of BTC upon osteogenesis was mediated by cells further committed to the osteoblastic phenotype by using MC3T3-E1 pre-osteoblasts. Similar to hMSC under osteogenic culture, Colla2 expression was reduced by BTC, although this did not achieve statistical significance (Fig. 1c). Thus, these data indicated that BTC, similar to EGF and EGF-like ligands TGF- $\alpha$ and amphiregulin, inhibited the differentiation of osteoprogenitor and osteoblastic cells.

\section{BTC increases MSC and pre-osteoblast proliferation}

Based on the reported evidence that EGF and EGF-like ligands amphiregulin and TGF- $\alpha$ increase osteoblast proliferation (Loza et al. 1995; Nicolas et al. 1990; Qin et al. 2005; VandePol et al. 1989), we sought whether decreased osteogenic differentiation in response to BTC was paralleled with changes in proliferation. hMSCs and MC3T3-E1 pre-osteoblasts were cultured in the presence of $0.5-$ $500 \mathrm{ng} / \mathrm{ml} \mathrm{BTC}$ for 4 days. Addition of BTC at $5 \mathrm{ng} / \mathrm{ml}$ significantly increased hMSC cell proliferation approximately 2.2-fold over spontaneous proliferation observed in BTC-free cultures (Fig. 2a); BTC doses other than $5 \mathrm{ng} / \mathrm{ml}$ had no significant effect on cell proliferation. Similarly, MC3T3-E1 cultures with BTC demonstrated a significant increase in proliferation compared with BTC-free cultures (Fig. 2b), revealing a two-fold increase in cell number in response to $5 \mathrm{ng} / \mathrm{ml}$ BTC. These data confirmed a stimulatory influence of BTC upon cell proliferation and further revealed that this process was independent of mesenchymal or osteoblastic phenotype.

BTC induction of proliferation is mediated through HIF- $\alpha$ stabilization

EGF and EGF-like ligands stimulate a host of intracellular signaling cascades, including MAPK and Akt. An intriguing cascade involves activation of the transcription factor HIF- $\alpha$ (Peng et al. 2006; Schultz et al. 2006; Tanaka et al. 2006), the genetic stabilization of which mediates increased bone mass (Wan et al. 2008; Wang et al. 2007). Culture of
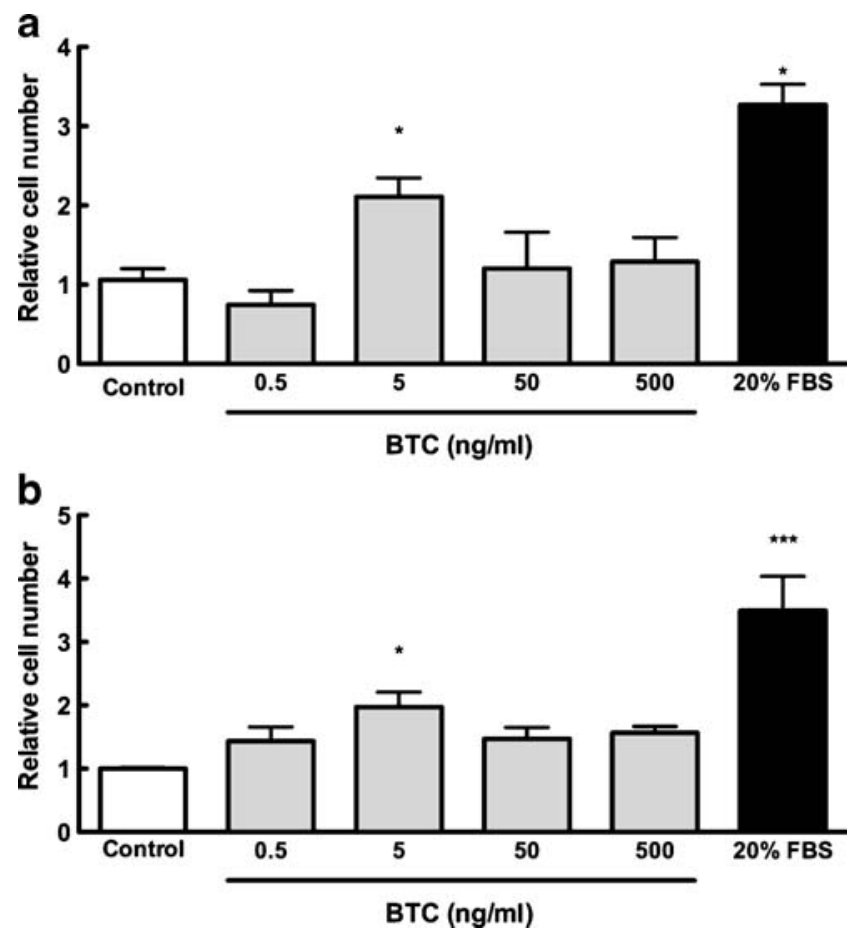

Fig. 2 BTC stimulates cell proliferation. hMSCs (a) or MC3T3-E1 pre-osteoblasts (b) were cultured in the presence of $0.5-500 \mathrm{ng} / \mathrm{ml}$ BTC for 4 days, after which time cells were trypsinized and counted. Addition of BTC at $5 \mathrm{ng} / \mathrm{ml}$ significantly enhanced proliferation compared with control cultures (white bar). Cell proliferation in response to $20 \%$ serum is shown as a positive control. Because of variation between experiments, data are presented as the fold-change compared with BTC-free control. Bars Means \pm SE. $* P<0.05$ compared with BTC-free culture; $* * P<0.001$ compared with all other cultures; $n=3-6$ per experiment per time point

hMSC with $5 \mathrm{ng} / \mathrm{ml} \mathrm{BTC}$ for $24 \mathrm{~h}$ revealed a trend for HIF$1 \alpha$ accumulation compared with BTC-free controls, although to a lesser degree than that observed in cells cultured with the hypoxia mimetic, $100 \mu \mathrm{M}$ cobalt chloride (Fig. 3a, b). This effect was transient and was not observed in cultures treated with BTC for $1,2,4$, or $48 \mathrm{~h}$ (data not shown), indicating a transient influence of BTC upon HIF$1 \alpha$ stabilization. Because stable HIF- $\alpha$ is associated with proliferation (as observed in tumorigenic culture; Gardner and Corn 2008; Rankin and Giaccia 2008; Wouters and Koritzinsky 2008), we investigated whether BTC-mediated increases in osteoprogenitor proliferation were mediated via HIF- $1 \alpha$ stabilization. We confirmed that the HIF- $\alpha$ antagonist YC-1 $(10 \mu \mathrm{M})$ prevented HIF-1 $\alpha$ stabilization in response to both hypoxia $\left(1 \% \mathrm{O}_{2}\right)$ or hypoxia mimetics $\left(100 \mu \mathrm{M} \mathrm{CoCl}_{2}\right.$; Fig. 3c). Co-culture of hMSC cells with the HIF- $\alpha$ antagonist YC-1 revealed a dose-dependent attenuation of $5 \mathrm{ng} / \mathrm{ml}$ BTC-mediated proliferation (Fig. 3d). The inhibitory influence of the same doses of YC-1 on HIF-1 $\alpha$ levels was confirmed by Western immunoblotting (data not shown). These findings indicated 
Fig. 3 Influence of HIF-1 $\alpha$ on BTC-driven proliferation. a hMSCs were cultured in the presence of $5 \mathrm{ng} / \mathrm{ml} \mathrm{BTC}$ or $100 \mu \mathrm{M} \mathrm{CoCl}_{2}$ for $24 \mathrm{~h}$, after which time whole-cell protein lysates were analyzed for HIF- $1 \alpha$, as normalized to $\beta$-actin. Treatment with BTC stabilized HIF- $1 \alpha$ levels compared with BTC-free controls. b Western immunoblotting showed increased HIF-1 $\alpha$ levels in BTC- and $\mathrm{CoCl}_{2}$-treated cells compared with control cultures. c Western immunoblotting demonstrated the induction of HIF- $1 \alpha$ expression in response to hypoxia $\left(1 \% \mathrm{O}_{2}\right)$ or hypoxia mimetics $\left(100 \mu \mathrm{M} \mathrm{CoCl}_{2}\right)$, whereas the addition of $10 \mu \mathrm{M}$ YC-1 prevented HIF- $1 \alpha$ stabilization under such conditions. d hMSCs were cultured in the presence of 0 $25 \mu \mathrm{M} \mathrm{YC}-1$ in the absence (white bars) or presence (black bars) of $5 \mathrm{ng} / \mathrm{ml} \mathrm{BTC}$. The addition of 10 or $25 \mu \mathrm{M} \mathrm{YC}-1$ attenuated BTCdriven proliferation. Because of variation between experiments, data are presented as fold change compared with BTC-free control. Bars Means \pm SE. ${ }^{*} P<0.05$ compared with BTC-free culture; $n=3-4$ experimental replicates

that the stimulatory effect of BTC upon cell proliferation was mediated by stabilized HIF- $\alpha$.

ErbB receptor expression in stem cells and pre-osteoblasts

The mRNA expression of ErbB receptor subtypes in hMSC and MC3T3-E1 was examined by quantitative PCR. We found that both naive (i.e., prior to further osteogenic differentiation) MSC and pre-osteoblasts express $E G F R /$ $\operatorname{ErbB1}$ (Fig. 4a), ErbB2 (Fig. 4b), and ErbB3 (Fig. 4c); no transcript for ErbB4 was observed (data not shown). All ErbB isoform receptors were expressed at higher levels in MSC than in MC3T3-E1, suggesting that osteogenic differentiation decreased ErbB expression, or that the levels changed as a function of immortalization. However, hMSCs cultured for 21 days under osteogenic or maintenance conditions revealed no significant differences in the transcript expression of ErbB1, ErbB2, or ErbB3 (not shown), suggesting that the relative differences in individual $\operatorname{ErbB}$ isoform expression was a species, rather than phenotypic, difference.

BTC does not influence osteoclast-regulating factors interleukin-6, osteoprotegerin, or RANKL

A potential explanation for the site-specific effects of BTC upon cortical and trabecular remodeling involves the regulation of osteoclast formation by osteoblasts. Thus, we examined the influence of BTC upon the expression of interleukin-6 (IL-6), osteoprotegerin (OPG), and receptor activator of NF- $\mathrm{kB}$ ligand (RANKL) in MSCs under osteogenic conditions. BTC had no effect upon IL-6 expression (Fig. 5a) and elicited a trend, albeit insignificant, for increased RANKL expression (Fig. 5b). In contrast, BTC at 50 or $500 \mathrm{ng} / \mathrm{ml}$ significantly decreased $O P G$ transcript after 7 days in culture (Fig. 5c); the inhibitory influence of BTC upon the $O P G$ transcript was transitory and was not observed after 14 or 21 days in culture. The significant

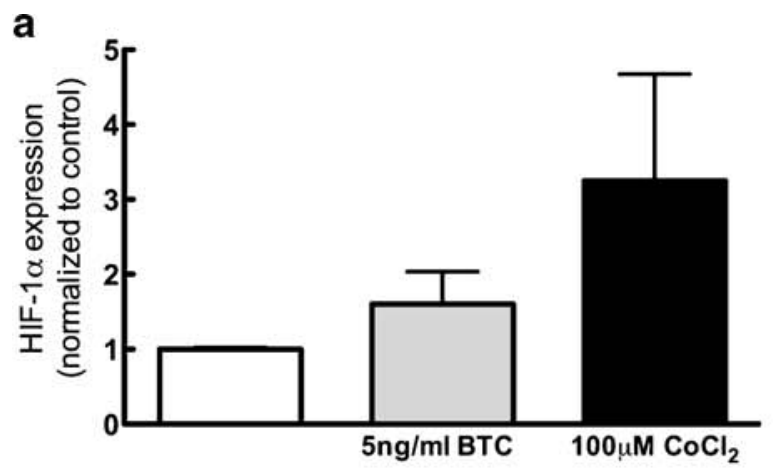

b

HIF $-1 \alpha$

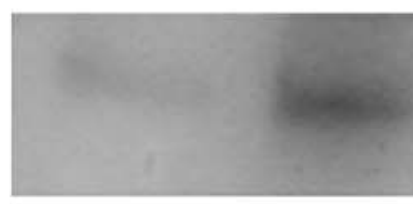

$\beta$-Actin
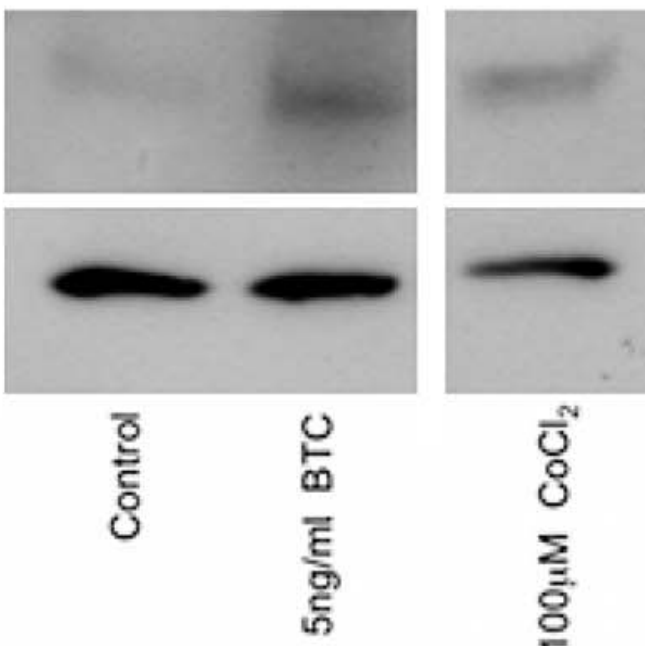

C
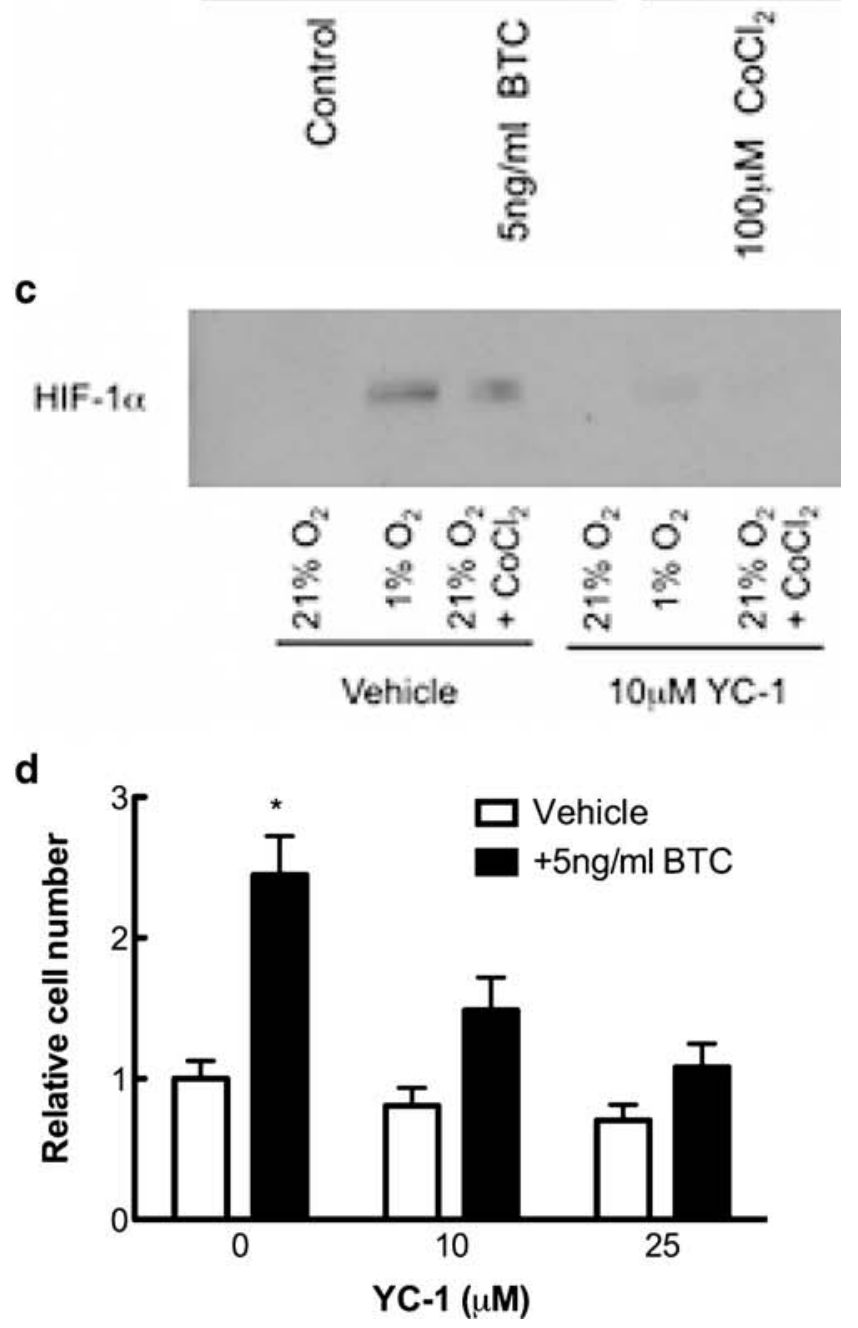
a
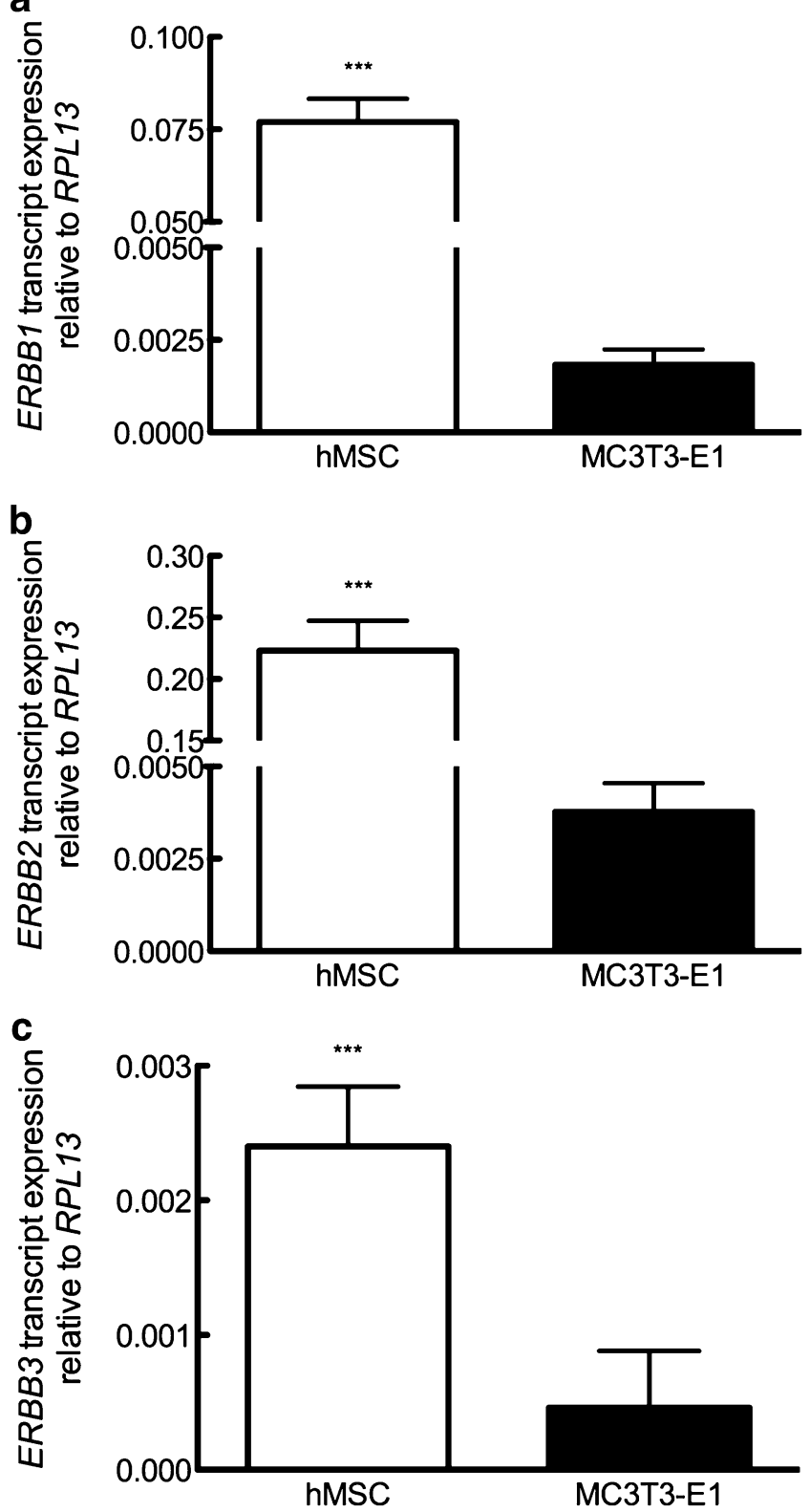

Fig. 4 Profile of $E R B B$ transcript expression. Expression of $E R B B 1$ (a), ERBB2 (b), and ERBB3 (c) isoform transcript in hMSC and MC3T3-E1 cells. Bars Means \pm SE. $* * * P<0.001$ compared with MC3T3-E1; $n=3-4$ per experiment per condition

reduction in $O P G$ transcript and the trend for the increased RANKL expression promoted a trend for increased $R A N K L / O P G$ ratios, thereby favoring osteoclastogenesis, although the trend did not achieve statistical significance (Fig. 5d)

\section{Discussion}

The debate regarding the influence of EGF and EGF-like ligands upon osteoblast function and differentiation is ongoing. Whereas these growth factors have been shown to reduce osteogenic differentiation (Antosz et al. 1987; Nicolas et al. 1990; Qin et al. 2005), a recent report by Schneider et al. (2009) has demonstrated that BTC transgenic mice exhibit increased endocortical bone appo-

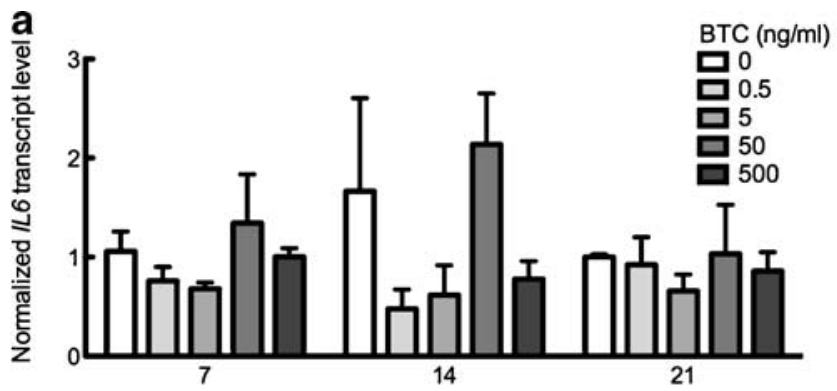

Days of osteogenic culture
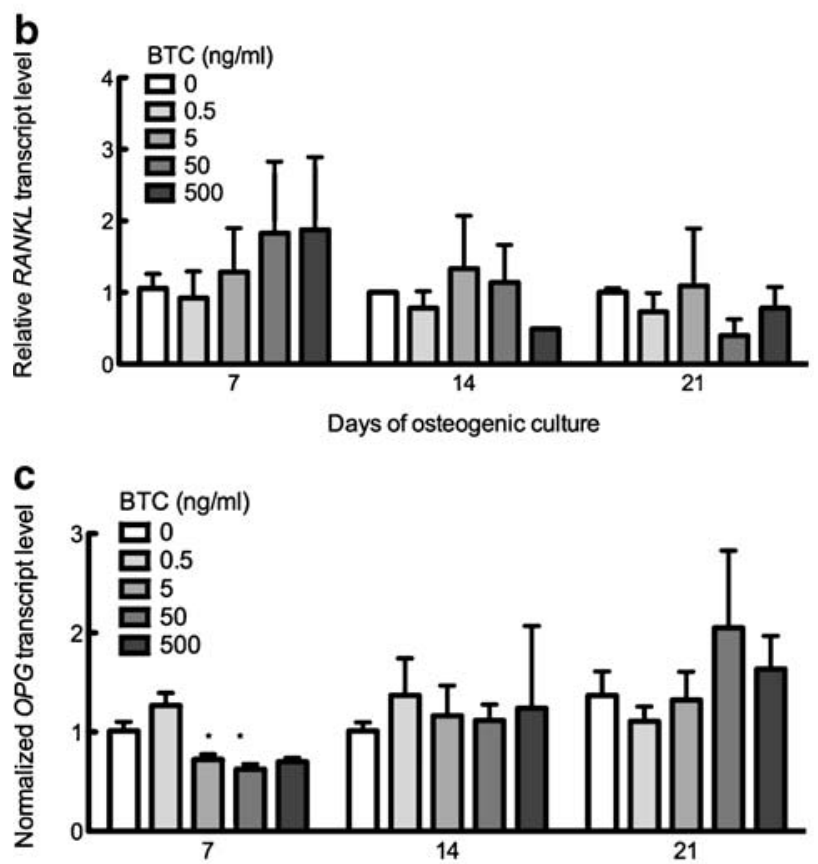

Days of osteogenic culture

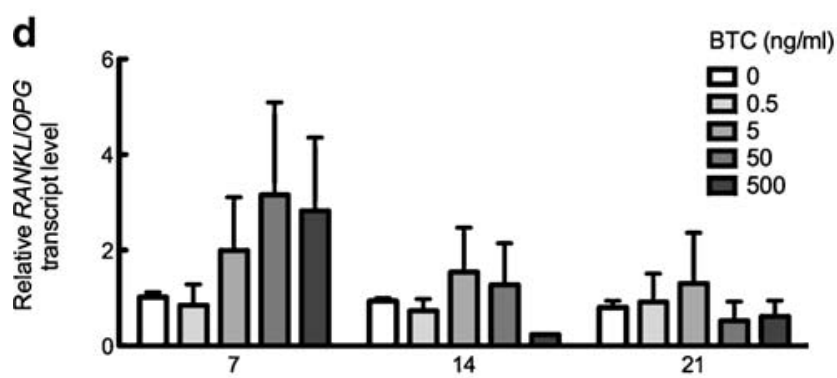

Days of osteogenic culture

Fig. 5 Influence of BTC upon osteoclast regulatory factors. hMSC were cultured under osteogenic conditions in the presence of 0.5 $500 \mathrm{ng} / \mathrm{ml} \mathrm{BTC}$ for 7-21 days, from which total RNA lysates were examined by qtPCR analysis for (a) $I L-6$, (b) $R A N K L$, (c) $O P G$, or (d) $R A N K L / O P G$. Bars Means \pm SE. $* P<0.05$ compared with BTC-free culture within same timepoint. $n=3-4$ per experiment per time point 
sition and femoral bone mineral density but also present with decreased trabecular bone mineral density. In order to begin to delineate the mechanisms producing these sitespecific effects of BTC, we have examined the influence of recombinant BTC upon the osteogenic differentiation of MSCs and committed pre-osteoblasts. We have found that BTC attenuates differentiation toward an osteogenic phenotype, as demonstrated by reductions in ALP activity and transcription of RUNX2 and COL1A1 (Fig. 1). Interestingly, we have observed no significant influence of BTC, regardless of dose, upon the expression of the mature osteoblast marker osteocalcin. Thus, BTC functions similar to EGF (Nicolas et al. 1990) and amphiregulin (Qin et al. 2005) to reduce osteogenic differentiation. Interestingly, the ability of EGF, and presumably of BTC, to attenuate cellular differentiation is not specific to the osteogenic phenotype, as EGF also decreases the chondrogenic and adipogenic differentiation of MSCs and, in doing so, reversibly maintains their multilineage potential (Krampera et al. 2005).

We have observed a mitogenic influence of BTC upon MSCs (Fig. 2a) and on committed pre-osteoblasts (Fig. 2b); co-culture with a pharmacologic antagonist, YC-1, which promotes HIF- $\alpha$ degradation and inhibits its de novo synthesis (Chun et al. 2004), dose-dependently attenuates the proliferative response of MSCs to BTC (Fig. 3d). HIF- $\alpha$ is a transcription factor that, under conditions of sufficient molecular oxygen (i.e., under normoxia), is targeted for proteasomal degradation; in contrast, under conditions of reduced molecular oxygen (hypoxia), HIF- $\alpha$ is stabilized, complexes with HIF- $\beta$, and translocates to the nucleus to induce gene expression. We have recently demonstrated that HIF- $1 \alpha$ is responsible for increases in EP1 prostanoid receptor under hypoxia (Genetos et al. 2009). Surprisingly, growth factors, similar to EGF and BTC, and hormones are able to stabilize HIF- $\alpha$ under non-hypoxic conditions. Fetal calf serum, thrombin, and angiotensin II all stabilize HIF$1 \alpha$ and promote its binding to DNA to induce gene transcription in vascular smooth muscle cells (Richard et al. 2000). Similarly, Schultz et al. (2006) have demonstrated that HIF- $1 \alpha$ contributes to the proliferative response of smooth muscle cells to fibroblast growth factor-2 and platelet-derived growth factor. Hypoxia exerts pleiotropic effects upon MSCs and has been implicated in the commitment toward chondrogenic (Kanichai et al. 2008) or neuronal (Pacary et al. 2006, 2007, 2008) lineages; in contrast, we have recently shown that hypoxia attenuates the osteogenic differentiation of MSCs (Raheja et al. 2009). Taken together, these data indicate that growth factor stabilization of HIF- $\alpha$ under nonhypoxic conditions promotes cell proliferation.

EGF and EGF-like ligands also influence skeletal remodeling by controlling bone resorption. Rats administered high doses of EGF reveal increased osteoclast number on trabecular bone surfaces (Marie et al. 1990), and $E G F$ transgenic mice produce thinner bones than wild-type controls (Chan and Wong 2000; Xian 2007). Interestingly, considerable controversy exists as to whether osteoclasts express receptors for EGF or EGF-like ligands. MartineauDoize et al. (1988) have demonstrated that osteoclasts fail to bind $\left[{ }^{125} \mathrm{I}\right]$-iodo-EGF, suggesting that osteoclasts lack EGF receptors; these findings have subsequently been confirmed by Zhu et al. (2007). In contrast, Yi et al. (2008) report that EGF-receptor increases during osteoclastogenesis in response to RANKL, and that EGF-receptor signaling is required for RANKL-mediated osteoclastogenesis. The most likely cell type influenced by EGF to affect osteoclasts or their precursors is the osteoblast, primarily because of the close microenvironment in which these cells act as neighbors and modulate osteoclast formation and activity. Osteoblasts regulate osteoclast formation via RANKL, OPG, and IL-6, among other cytokines. Zhu et al. (2007) have demonstrated that EGF indirectly stimulates osteoclast formation via the decreased OPG expression by osteoblasts; similarly, we have observed a transient inhibitory influence of BTC upon $O P G$ expression, but no influence upon $R A N K L$ transcription. Consequently, the ratio of the $R A N K L / O P G$ transcript demonstrates a trend above unity, indicating a stimulatory effect upon osteoclastogenesis.

EGF ligand binding induces manifold cellular responses depending upon the ErbB receptors mobilized. We have found that both MSCs and committed pre-osteoblasts express three of the four EGF receptors, lacking any expression of ErbB4. Among the three ErbB isoforms found within these cells, ErbB2 is maximally expressed, followed by ErbB1; ErbB3 is also expressed, albeit at approximately 25-fold lower levels than ErbB2 (Fig. 4a, c). Osteogenic differentiation has revealed no significant change in ErbB isoform expression (Fig. 4a-c). Based upon a Scatchard analysis revealing the $\mathrm{K}_{\mathrm{D}}$ of ErbB1 and BTC as $0.5 \mathrm{nM}(4.5 \mathrm{ng} / \mathrm{ml})$ in $3 \mathrm{~T} 3$ cells (Watanabe et al. 1994), our chosen doses of $0.5,5,50$, and $500 \mathrm{ng} / \mathrm{ml}$ correspond to, approximately, $10 \%, 50 \%, 90 \%$, and $99 \%$ ErbB1 receptor occupancy, respectively. The lack of expression of ErbB4, a binding partner for BTC, in MSC or pre-osteoblasts indicates that the stimulatory influence of BTC upon proliferation and its inhibitory effect upon differentiation is mediated by ErbB1 homodimers or ErbB1/ErbB2 heterodimer or, potentially, an ErbB2/ErbB3 heterodimer (Pinkas-Kramarski et al. 1998). Indeed, each of these processes (increased proliferation and attenuated differentiation) are probably regulated by a different ErbB receptor complex, because of the variable affinity of ErbB1 and ErbB2 for ligands.

Our findings do not however reveal the mechanisms that explain site-specific differences in cortical formation and 
trabecular resorption in BTC transgenic mice. The most likely scenario results from the different microenvironments in which osteoblasts reside in cortical versus trabecular bone: osteoblasts within a remodeling compartment in cancellous bone are intimately exposed to a cytokine-rich red-marrow milieu, whereas osteoblasts within cortical bone are controlled more by mechanical or systemic factors such as parathyroid hormone (PTH) and $1 \alpha, 25-(\mathrm{OH})_{2}$ vitamin $\mathrm{D}_{3}$ (Mundy 1999). Indeed, vitamin $\mathrm{D}_{3}$ has been shown to enhance osteoblast maturation in response to EGF (Yarram et al. 2004), and PTH induces EGF and EGF-like ligand expression (Qin and Partridge 2005; Qin et al. 2005; Swarthout et al. 2001; Xian 2007). In contrast, localized factors present within the bone marrow stroma, such as insulin-like growth factor (IGF), decrease osteoblast differentiation and instead promote proliferation (VandePol et al. 1989). IGF is a powerful regulator of post-natal bone growth, and EGF regulates IGF and IGF-binding protein (IGFBP) levels (Xian 2007). In further support of this possibility, reductions in body weight that occur in $E G F$ transgenic mice are associated with serum IGFBP-3 levels (Chan and Wong 2000). Thus, an unexamined scenario is whether the stunted growth observed in $E G F$ and $B T C$ transgenics is indirectly mediated through altered IGF bioavailability.

This study has revealed that BTC stimulates the proliferation and inhibits the osteogenic differentiation of both MSCs and committed pre-osteoblasts. This stimulatory influence of BTC upon mesenchymal proliferation is mediated via the stabilization of HIF-1 $\alpha$. We have found that MSCs and committed osteoprogenitors express ErbB1, ErbB2, and ErbB3 but fail to express ErbB4; we have observed no change in the expression of these receptors under osteogenic conditions. Whereas previous work has demonstrated the influence of EGF, TGF- $\alpha$, and amphiregulin upon osteoblast proliferation, our data are the first to reveal a similar role for BTC and are the first to provide a mechanistic explanation involving HIF-1 $\alpha$.

Acknowledgements The authors are grateful to Chrisoula A. Toupadakis for critical review of the manuscript, to Prof. David P. Fyhrie for helpful comments on cortical and cancellous bone growth, and to Prof. Jeffrey M. Gimble for general discussion.

Open Access This article is distributed under the terms of the Creative Commons Attribution Noncommercial License which permits any noncommercial use, distribution, and reproduction in any medium, provided the original author(s) and source are credited.

\section{References}

Antosz ME, Bellows CG, Aubin JE (1987) Biphasic effects of epidermal growth factor on bone nodule formation by isolated rat calvaria cells in vitro. J Bone Miner Res 2:385-393
Chan SY, Wong RW (2000) Expression of epidermal growth factor in transgenic mice causes growth retardation. J Biol Chem 275:38693-38698

Chien HH, Lin WL, Cho MI (2000) Down-regulation of osteoblastic cell differentiation by epidermal growth factor receptor. Calcif Tissue Int 67:141-150

Chun YS, Yeo EJ, Park JW (2004) Versatile pharmacological actions of YC-1: anti-platelet to anticancer. Cancer Lett 207:1-7

Citri A, Yarden Y (2006) EGF-ERBB signalling: towards the systems level. Nat Rev Mol Cell Biol 7:505-516

Gardner LB, Corn PG (2008) Hypoxic regulation of mRNA expression. Cell Cycle 7:1916-1924

Genetos DC, Lee CM, Wong A, Yellowley CE (2009) HIF-1alpha regulates hypoxia-induced EP1 expression in osteoblastic cells. J Cell Biochem 107:233-239

Harris RC, Chung E, Coffey RJ (2003) EGF receptor ligands. Exp Cell Res 284:2-13

Kanichai M, Ferguson D, Prendergast PJ, Campbell VA (2008) Hypoxia promotes chondrogenesis in rat mesenchymal stem cells: a role for AKT and hypoxia-inducible factor (HIF)-1alpha. J Cell Physiol 216:708-715

Krampera M, Pasini A, Rigo A, Scupoli MT, Tecchio C, Malpeli G, Scarpa A, Dazzi F, Pizzolo G, Vinante F (2005) HB-EGF/HER-1 signaling in bone marrow mesenchymal stem cells: inducing cell expansion and reversibly preventing multilineage differentiation. Blood 106:59-66

Livak KJ, Schmittgen TD (2001) Analysis of relative gene expression data using real-time quantitative PCR and the 2(-Delta Delta C (T)) method. Methods 25:402-408

Loza J, Carpio L, Lawless G, Marzec N, Dziak R (1995) Role of extracellular calcium influx in EGF-induced osteoblastic cell proliferation. Bone 16:341S-347S

Marie PJ, Hott M, Perheentupa J (1990) Effects of epidermal growth factor on bone formation and resorption in vivo. Am J Physiol 258:E275-E281

Martineau-Doize B, Lai WH, Warshawsky H, Bergeron JJ (1988) In vivo demonstration of cell types in bone that harbor epidermal growth factor receptors. Endocrinology 123:841-858

Mundy GR (1999) Bone remodeling. In: Favus MJ (ed) Primer on the metabolic bone diseases and disorders of mineral metabolism. Lippincott Williams \& Wilkins, Philadelphia

Nicolas V, Nefussi JR, Collin P, Forest N (1990) Effects of acidic fibroblast growth factor and epidermal growth factor on subconfluent fetal rat calvaria cell cultures: DNA synthesis and alkaline phosphatase activity. Bone Miner 8:145-156

Pacary E, Legros H, Valable S, Duchatelle P, Lecocq M, Petit E, Nicole O, Bernaudin M (2006) Synergistic effects of $\mathrm{CoCl}_{2}$ and ROCK inhibition on mesenchymal stem cell differentiation into neuron-like cells. J Cell Sci 119:2667-2678

Pacary E, Tixier E, Coulet F, Roussel S, Petit E, Bernaudin M (2007) Crosstalk between HIF-1 and ROCK pathways in neuronal differentiation of mesenchymal stem cells, neurospheres and in PC12 neurite outgrowth. Mol Cell Neurosci 35:409-423

Pacary E, Petit E, Bernaudin M (2008) Concomitant inhibition of prolyl hydroxylases and ROCK initiates differentiation of mesenchymal stem cells and PC12 towards the neuronal lineage. Biochem Biophys Res Commun 377:400-406

Peng XH, Karna P, Cao Z, Jiang BH, Zhou M, Yang L (2006) Crosstalk between epidermal growth factor receptor and hypoxiainducible factor-1alpha signal pathways increases resistance to apoptosis by up-regulating survivin gene expression. J Biol Chem 281:25903-25914

Pinkas-Kramarski R, Lenferink AE, Bacus SS, Lyass L, Poll ML van de, Klapper LN, Tzahar E, Sela M, Zoelen EJ van, Yarden Y (1998) The oncogenic ErbB-2/ErbB-3 heterodimer is a surrogate 
receptor of the epidermal growth factor and betacellulin. Oncogene 16:1249-1258

Qin L, Partridge NC (2005) Stimulation of amphiregulin expression in osteoblastic cells by parathyroid hormone requires the protein kinase A and cAMP response element-binding protein signaling pathway. J Cell Biochem 96:632-640

Qin L, Tamasi J, Raggatt L, Li X, Feyen JH, Lee DC, Dicicco-Bloom E, Partridge NC (2005) Amphiregulin is a novel growth factor involved in normal bone development and in the cellular response to parathyroid hormone stimulation. J Biol Chem 280:3974-3981

Raheja LF, Genetos DC, Yellowley CE (2009) The effect of oxygen tension on the long-term osteogenic differentiation and MMP/ TIMP expression of human mesenchymal stem cells. Cells Tissues Organs (in press)

Rankin EB, Giaccia AJ (2008) The role of hypoxia-inducible factors in tumorigenesis. Cell Death Differ 15:678-685

Richard DE, Berra E, Pouyssegur J (2000) Nonhypoxic pathway mediates the induction of hypoxia-inducible factor 1alpha in vascular smooth muscle cells. J Biol Chem 275:26765-26771

Schneider MR, Dahlhoff M, Herbach N, Renner-Mueller I, Dalke C, Puk O, Graw J, Wanke R, Wolf E (2005) Betacellulin overexpression in transgenic mice causes disproportionate growth, pulmonary hemorrhage syndrome, and complex eye pathology. Endocrinology 146:5237-5246

Schneider MR, Mayer-Roenne B, Dahlhoff M, Proell V, Weber K, Wolf E, Erben RG (2009) High cortical bone mass phenotype in betacellulin transgenic mice is EGFR dependent. J Bone Miner Res 24:455-466

Schultz K, Fanburg BL, Beasley D (2006) Hypoxia and hypoxiainducible factor-1alpha promote growth factor-induced proliferation of human vascular smooth muscle cells. Am J Physiol Heart Circ Physiol 290:H2528-H2534

Swarthout JT, Doggett TA, Lemker JL, Partridge NC (2001) Stimulation of extracellular signal-regulated kinases and proliferation in rat osteoblastic cells by parathyroid hormone is protein kinase C-dependent. J Biol Chem 276:7586-7592

Tanaka H, Yamamoto M, Hashimoto N, Miyakoshi M, Tamakawa S, Yoshie M, Tokusashi Y, Yokoyama K, Yaginuma Y, Ogawa K (2006) Hypoxia-independent overexpression of hypoxiainducible factor 1alpha as an early change in mouse hepatocarcinogenesis. Cancer Res 66:11263-11270
VandePol C, Schlaeger D, Wong GL (1989) Mitogenic responses to and binding of insulin-like growth factor 1 and/or epidermal growth factor by bone cells. Bone Miner 5:371-382

Wan C, Gilbert SR, Wang Y, Cao X, Shen X, Ramaswamy G, Jacobsen KA, Alaq1 ZS, Eberhardt AW, Gerstenfeld LC, Einhorn TA, Deng L, Clemens TL (2008) Activation of the hypoxiainducible factor-1alpha pathway accelerates bone regeneration. Proc Natl Acad Sci USA 105:686-691

Wang Y, Wan C, Deng L, Liu X, Cao X, Gilbert SR, Bouxsein ML, Faugere MC, Guldberg RE, Gerstenfeld LC, Haase VH, Johnson RS, Schipani E, Clemens TL (2007) The hypoxia-inducible factor alpha pathway couples angiogenesis to osteogenesis during skeletal development. J Clin Invest 117:1616-1626

Watanabe T, Shintani A, Nakata M, Shing Y, Folkman J, Igarashi K, Sasada R (1994) Recombinant human betacellulin. Molecular structure, biological activities, and receptor interaction. J Biol Chem 269:9966-9973

Wong RW, Kwan RW, Mak PH, Mak KK, Sham MH, Chan SY (2000) Overexpression of epidermal growth factor induced hypospermatogenesis in transgenic mice. J Biol Chem 275:18297-18301

Wouters BG, Koritzinsky M (2008) Hypoxia signalling through mTOR and the unfolded protein response in cancer. Nat Rev Cancer 8:851-864

Xian CJ (2007) Roles of epidermal growth factor family in the regulation of postnatal somatic growth. Endocr Rev 28:284-296

Yarden Y (2001) The EGFR family and its ligands in human cancer. Signalling mechanisms and therapeutic opportunities. Eur J Cancer 37 (Suppl 4):S3-S8

Yarden Y, Sliwkowski MX (2001) Untangling the ErbB signalling network. Nat Rev Mol Cell Biol 2:127-137

Yarram SJ, Tasman C, Gidley J, Clare M, Sandy JR, Mansell JP (2004) Epidermal growth factor and calcitriol synergistically induce osteoblast maturation. Mol Cell Endocrinol 220:9-20

Yi T, Lee HL, Cha JH, Ko SI, Kim HJ, Shin HI, Woo KM, Ryoo HM, Kim GS, Baek JH (2008) Epidermal growth factor receptor regulates osteoclast differentiation and survival through crosstalking with RANK signaling. J Cell Physiol 217:409-422

Zhu J, Jia X, Xiao G, Kang Y, Partridge NC, Qin L (2007) EGF-like ligands stimulate osteoclastogenesis by regulating expression of osteoclast regulatory factors by osteoblasts: implications for osteolytic bone metastases. J Biol Chem 282:26656-26664 